\title{
Effect of the corrosion on Thin Films Nanostructured of Stainless Steel 304 Deposited by Magnetron Sputtering.
}

\author{
C.lópez-Meléndez ${ }^{1,2}$, C. Carreño-Gallardo ${ }^{2}$ and H.E. Esparza-Ponce ${ }^{2}$ \\ 1. Universidad La Salle Chihuahua. Prolongación Lomas de Majalca No. 11201 Col. Labor de Terrazas \\ C.P. 31020 Chihuahua, Chih. México. \\ 2. Centro de Investigación en Materiales Avanzados, S.C. Miguel de Cervantes 120, Complejo Industrial \\ Chihuahua C.P. 31109 Chihuahua, Chih. México
}

Recent research applies the technique magnetron sputtering to deposit thin films, improving corrosion resistance on the surface of the substrate, it has been found that the thin films with grain size refinement surface hardens, the substrate temperature has a direct relationship with the microstructure formed improved the mechanical properties [1,2]. The deposit for magnetron sputtering allows you to deposit a more uniform and stable coating free of dislocations, cristallography imperfections than other conventional methods. Recently this technique has been applied to austenitic stainless steels which are very important in engineering since they possess a great chemical stability, in applications where a combination of high resistance is needed against corrosion, conformability and soldering [3], particularly for its excellent resistance to corrosion in aggressive environments [4]. Few research report the behavior to corrosion nanostructured films of this stainless steel on a substratum of the same steel, the electrochemical techniques as potentiodynamic polarization curves and electrochemical noise have been of great use to analyze the susceptibility to corrosion in different materials.

The aim this work was to study the thin films of stainless steel 304 on substrates the similar steel. The nanostructured films were generated by magnetron sputtering in a sputtering system with a source of pulsed direct current. The nanostructured deposit temperatures were subjected at 25,100 and $200^{\circ} \mathrm{C}$. The target, obtained from the atoms eroded and the substrate is an AISI 304 stainless steel. The chemical composition of 17.75 wt. $\% \mathrm{Cr}, 7.77$ wt.\%Ni, 1.37 wt.\%Mn, 0.370 wt.\%Si, 0026 wt.\%C. the balance Fe. Pre-deposit preparation was grinding to $1000 \mathrm{SiC}$ grit is degreased with acetone. In this experiment the variable of interest was the temperature of deposit at three different temperatures 25,100 and $200^{\circ} \mathrm{C}$ (three specimens were made for each temperature of deposit). For one thin film was characterized for scanning electron microscope (SEM).

The thickness and adhesion of the films were analyzed by SEM. Figure 1 shows three images where the average thickness was about $200 \mathrm{~nm}$. An optimal adhesion was not observed in figures 1a, 1b and 1c. Although there were good adhesion areas, some other areas did not show such adhesions due to the roughness of the substrate

The corrosion behavior of the thin films $304 \mathrm{SS}$ was determined by potentiodynamic polarization curves on a Solartron 1287 electrochemical interface using a platinum foil as the counter electrode and a saturated calomel electrode (SCE) as reference electrode. The working electrode consisted of base metal with the nanostructured thin film at different deposition temperatures. The polarization curves were measured from the cathodic to anodic area with a potential sweep rate of $1 \mathrm{mVs}-1$. The results showed that the deposition temperature definitely influences the morphology of this thin film, at temperature of $100^{\circ} \mathrm{C}$, presenting a higher corrosion resistance. 

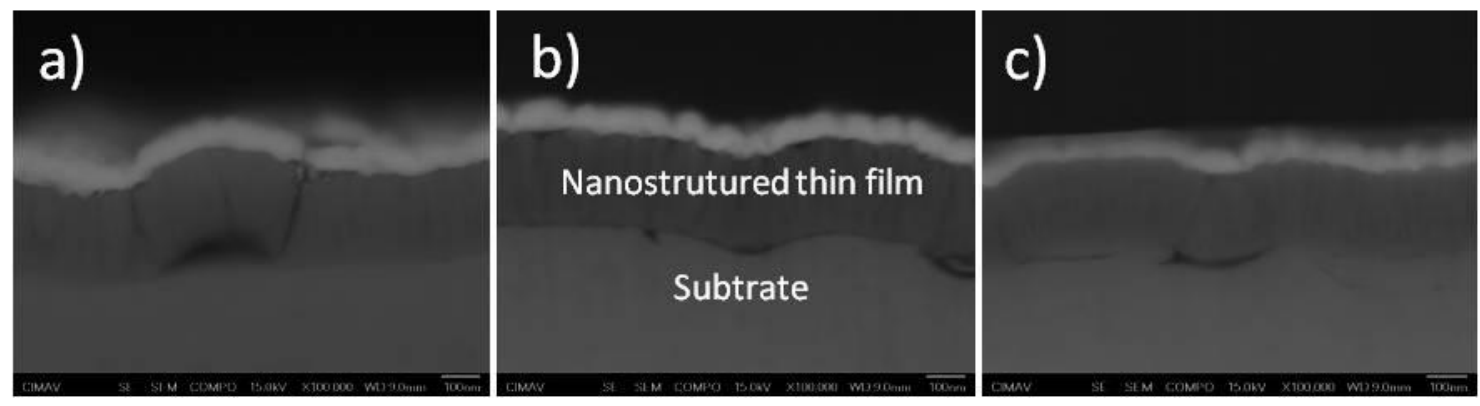

Figure 1. SEM Cross sectional morphology nanostructures films: (a) with temperature to deposited $25^{\circ} \mathrm{C}$, (b) with temperature to deposited $100^{\circ} \mathrm{C}$ and (c) with temperature to deposited $200^{\circ} \mathrm{C}$.

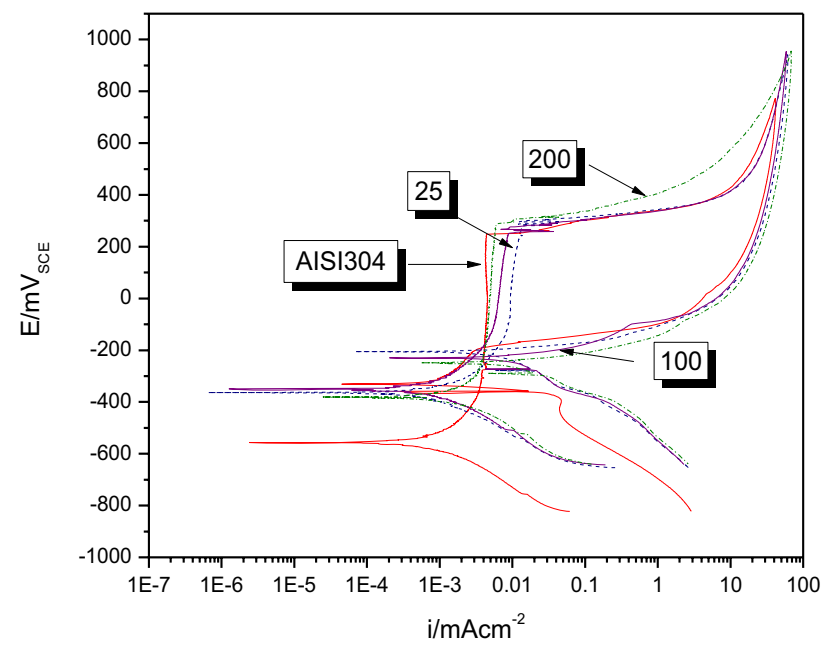

Figura 2. Potentiodynamic polarization curves of thin films AI304 to different deposit temperature: 25,100 y $200^{\circ} \mathrm{C}$ immerse in $\mathrm{NaCl}$ to $5 \%$ solution

[1] X.Peng, J Yan, y. Zhou and R, Wang, Acta Materialia, 53 (2005).

[2] Hai-Bo Lu, Ying Li and Fu-Hui Wang, Thin Solid Films, 510 (2006) 197-202.

[3] ASM Handbook, Properties and Selection: Irons, Steels, and High Performance Alloy, American Society of Metals, Vol. 1, 10th Edition, (1993).

[4] Morteza Zandrahimi, M. Reza Bateni, A. Poladi, Jerzy and A. Szpunar, Wear, 263 (2007) 674-678. 